\title{
Ainda (e sempre) Saussure: história, memória e discurso em três versões de um mesmo texto
}

\section{Still (and always) Saussure: history, memory and discourse in three versions of the same text}

\author{
Amanda Eloina Scherer \\ Maria Iraci Sousa Costa² \\ 1,2 Universidade Federal de Santa Maria, Programa de Pós-Graduação em Letras,
}

Professora titular de Linguística junto ao Departamento de Letras Clássicas e Linguística da Universidade Federal de Santa Maria (UFSM). Coordenadora geral do Laboratório Corpus e professora do Programa de Poss-Graduaçao em Letras da UFSM.

Entps://orcid. org/0000-0002-7183-805X

Pom Pós-Graduação sob supervisão da Professora Dra. Amanda Eloina

Scherer.

(ii) https://orcid.org/0000-0002-5551-4557

E-mail: iraciscosta@yahoo.com.br
RESUMO: No presente artigo, desenvolveremos uma reflexão acerca do contexto de produção de três versões do Curso de Linguística Geral (CLG) a saber, a versão publicada na Argentina e aquelas publicadas no Brasil e em Portugal. Nosso objetivo é compreender como o CLG é recebido/lido em cada momento histórico fora do contexto francês. Selecionamo-las não só pela relação singular com a língua, mas porque elas são propostas em conjunturas em que o CLG é recebido/lido de forma diferente. Além disso, nas referidas publicações, consideraremos também uma passagem que é bastante controversa, mesmo na edição francesa, aquela que trata do exemplo dado para ilustrar o princípio do arbitrário do signo. Ao comparar essa passagem nas diferentes situações, queremos entender como se inscreve o gesto de interpretação do sujeito que se responsabilizou pela versão da obra em cada um dos países em questão.

Palavras-chave: CLG; Versões; Publicações; Horizonte de retrospecção e projeção.

ABSTRACT: In this article we reflect about the context of three versions of the Cours de Linguistique Générale (CLG): the one published in Argentina and those published in Brazil and Portugal. Our objective is to comprehend how CLG is received/read in each historical moment outside the French context. We selected these three versions not only for their unique relation with their languages, but because they are proposed in circumstances in which the CLG is received/read in a different way. Furthermore, in these versions we also consider a quite controversial passage, even in the French edition, the one that deals with the example given to illustrate the principle of the sign's arbitrariness. While comparing this passage in different versions we understand how the interpretation gesture of the individual who took the responsibility for the work's version is inscribed in each one of the countries concerned.

Keywords: $C L G$; Versions; Publications; Retrospection and projection horizon. 


\section{Situando nosso objeto}

m 2016, comemoramos os 100 anos da primeira publicação do Curso de Linguística Geral de Ferdinand de Saussure. 100 anos da publicação francesa do Curso. 100 anos de história e de memória, espaço onde sujeito e discurso entrelaçam-se na constituição do disciplinar das Ciências Humanas no século XX e XXI. 100 anos de um percurso disciplinar na formação e na constituição do que hoje nomeamos e, por consequência, designamos como Linguística Moderna. No entanto, apesar desses eventos, mas sem deixar de considerá-los em sua grandeza e importância, questionamonos de que forma essa obra, a partir da edição e publicação francesas, vai ajudar a compor a história ocidental da referida disciplina - principalmente naqueles/nesses países circunscritos em/por/a um território e/ou em um continente, como é o caso do mundo brasileiro, do argentino e do português - já que chega indistintamente, em tempos não coincidentes, nesses diferentes espaços? Além disso, observando que cada uma dessas edições reinscreve, pelas condições de produção que lhe são próprias, a (sua) história da e na linguística saussuriana com certa singularidade, em uma alteridade sem limite, como poderemos entender - em termos de - a legitimação da produção do conhecimento sobre a linguagem em cada um dos espaço-tempo referidos, do ponto de vista histórico dessa publicação?

Para tanto, estamos propondo um estudo da historicização dos textos iniciais dessas versões - os quais cumprem a função de encaminhá-las e de comentar sobre elas - para tentar, por meio desses ditos, compreender as formas de nomeação e de designação dessa obra e do mestre genebrino nos contextos por nós já indicados. Em outras palavras, estamos propondo compreender o que tais textos acrescentam ao horizonte de retrospecção (AUROUX, 2006) e o que precisamos levar em conta e que poderíamos nomear como horizonte de projeção (AUROUX, 2006) naquilo que configuraria um projeto de autonomia de certa ciência da linguagem, chamada, na época, de Semiologia. Queremos problematizar esses textos que não só constam na, mas antecipam a versão do CLG, quando da sua publicação em países como Brasil, Portugal e Argentina, para entender como a referida obra é recebida/lida em cada momento histórico, fora do contexto francês. Selecionamos as versões argentina, brasileira e portuguesa não só pela relação singular com a língua, mas também porque elas são colocadas em conjunturas em que o CLG é recebido/lido de forma diferente.

Por outro lado, vamos também considerar, nas referidas versões, uma passagem da obra em si do CLG que é bastante controversa, mesmo na edição francesa, a saber, aquela do exemplo dado para ilustrar o princípio do arbitrário do signo. Ao comparar essa passagem em diferentes versões, vamos procurar entender como se inscreve o gesto de interpretação daquele sujeito que se responsabilizou pela versão da obra em cada um dos países em questão.

Além das questões já colocadas, referimos que vamos tentar evitar, de toda forma possível, a ideologia de uma gênese com a sua corte de precursores, influências, avanços, continuidades. Vamos procurar nos afastar, também, do princípio de totalidade, para não ficarmos presos a um saussurianismo exacerbado, mesmo sabendo que sujeito e ciência estão longe de um possível controle, controle do dizer e do pensar. Vamos nos lançar à reflexão sobre o efeito da constituição disciplinar a devir, tentando não homogeneizar, sob uma mesma etiqueta, percursos tão diferentes de versões e publicações, produtos de sentido para cada contexto concernido e objetivado aqui neste estudo. E, por último, vamos procurar entender de que forma tais textos iniciais, que antecedem a versão do CLG, inscrevem-se em uma configuração conceitual própria - ideológica e institucional - onde 
cada uma nasce sob o fundo de um certo relativismo, algumas vezes por demais contundente.

Para nós, existe aí uma convenção no modo como o historicismo fundase quase sempre em uma perspectiva de seguidor e ou de contextualizador do referido Curso. Veremos que essas duas perspectivas vêm juntas na ordem da formulação do texto inicial, tocando muito de perto quando da circulação dessa obra, constituindo sentidos outros para o disciplinar da Linguística em cada país e língua estudados.

Estamos propondo tal estudo e reflexão a partir do que, no Brasil, aprendemos a nomear como campo de um saber disciplinar, que é o da História das Ideias Linguísticas, levando em conta a sua relação, na questão interpretativa, com o disciplinar da Análise de Discurso de leitura pecheuxtiana (PÊCHEUX, 1990). Tal relação fundase nos trabalhos de Eni Orlandi e de seu grupo de pesquisadores a partir do projeto internacional do qual participamos ativamente.

\section{Situando nossa problemática de leitura}

Abordar diferentes versões do CLG, em conjunturas diversas, implica também refletir sobre distintas leituras e recepções do CLG. Trata-se de uma obra que se tornou um clássico (TRABANT, 2005) entre os linguistas e que, poderíamos ousar pensar, talvez não tenha deixado de ser mencionada, em seu título, em um único continente.

Fonte: Elaboração nossa.
De todo modo, não propomos aqui traçar um mapa das versões do CLG; nosso objetivo, pois, é bem mais modesto: propomos uma reflexão sobre os textos iniciais de três versões do CLG: a brasileira, a portuguesa e a argentina. Ainda que nossa questão não seja pensar um mapa das traduções do CLG, somos tentados a imaginar como poderia sê-lo, sob o pretexto de situar o nosso leitor acerca de quais versões abordaremos. Vejamos uma possível representação disso.

Figura 1 - Mapa das traduções do CLG

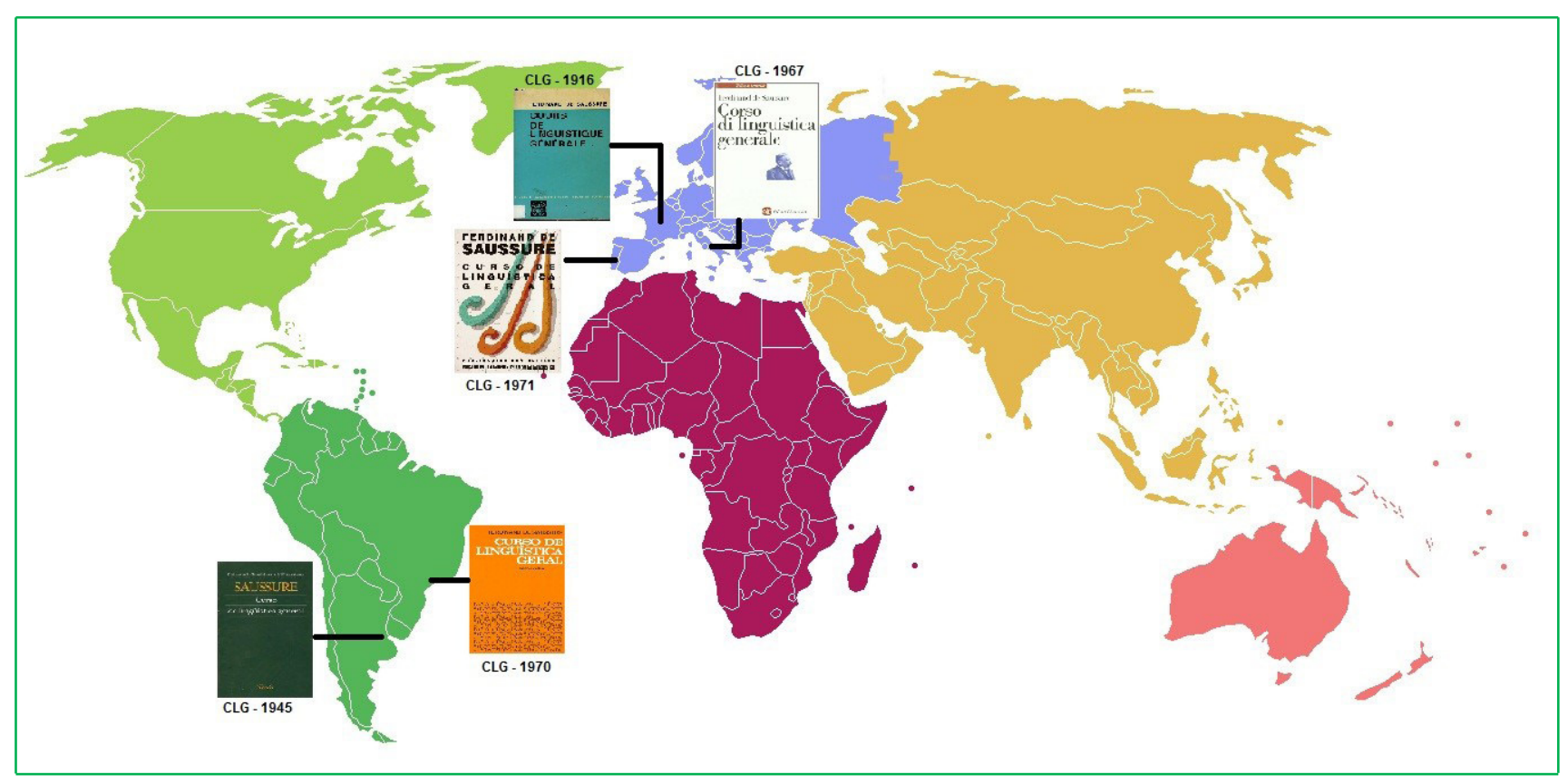


No mapa (Figura 1), destacamos não só as versões que iremos estudar aqui, mas também a primeira edição francesa (1916), assim como a edição italiana (1967), cujo texto introdutório, elaborado por Tullio de Mauro, passou a fazer parte, depois, de uma nova edição francesa (1972). Cabe destacar que as versões de que vamos tratar foram publicadas, primeiramente, na América do Sul, no que os europeus costumavam chamar de "Novo Mundo". Segundo rezam os dados históricos, a nomeação "Novo Mundo" foi cunhada pelo historiador Pietro Martire d'Anghiera, na obra De Orbe Novo (1530), para se referir ao que hoje é designado como Continente Americano. Sabemos também, pela narrativa histórica dos colonizadores europeus, que o "Novo Mundo" foi "descoberto" e colonizado pelos seus descobridores. Com eles, ainda, vieram suas línguas, que aqui, no "Novo Mundo", foram aos poucos tomando matizes próprias, com novas cores e outros sabores, nomeando novas nações e construindo novas utopias. Uma delas, a utopia da língua e do nome a ela dado. Sabemos que somos a língua que falamos, somos também tomados pela língua que nos foi imposta, pela colonização; somos, assim, parte de uma história do "Velho Mundo" no "Novo Mundo", na constituição de nosso imaginário/simbólico do que somos enquanto língua e nação.

A relação da língua e do sujeito aflorou-nos ainda mais neste artigo, pois vamos tentar dar conta de versões em três línguas outras daquela publicada na França. Aflorou-nos porque não podemos ficar impunes/imunes quando tivemos que tomar partido por não nomear a língua, mas a nação, para podermos falar da versão na língua que queremos estudar. E veremos, mais à frente, que isso também nos deu a ver a importância de tal posição política na forma, por exemplo, como um dos responsáveis pela versão na Argentina, Amado Alonso, coloca-se quando vai procurar explicitar um dos exemplos sobre o arbitrário do signo. Embora naturalizado argentino, o seu inconsciente faz vir à tona, para a comunidade argentina, algo que é da ordem de sua terra materna, a Espanha. A alteridade sem limites que trazíamos antes.

É preciso que explicitemos outro importante ponto: do mesmo modo que procuramos politicamente não trabalhar com a nomeação da língua - língua espanhola, língua portuguesa, por exemplo -, procuramos trazer aqui a nomeação versão em lugar da de tradução. Se estamos tomados pelo político na política de línguas quando da nomeação da língua, como pensar a versão e não a tradução? Para nós, temos aí uma problemática que ultrapassar um simples versar, no sentido tradicional, de passar de uma língua para outra, mas no sentido de que versar carrega algo mais que um simples ato de passagem. Versar carrega um processo singular de leitura que faz com que cada um dos sujeitos, produzindo a sua versão do CLG, esteja tomado pela língua, aquela da França e também pela sua, aquela da Argentina, do Brasil e de Portugal, e esse sujeito não faz isso ingenuamente, tampouco linearmente. Foi preciso elaborar e reelaborar, na sua própria língua, os exemplos trazidos na publicação do Curso na primeira versão, na França. Portanto, por versão, compreendemos algo que é sempre da ordem de um possível, nunca do definitivo. $\mathrm{O}$ espanhol-argentino, os brasileiros e o português tentam, a toda a prova, compreender o raciocínio do mestre genebrino para tentar acertar as nervuras de algo que está na e sobre a língua, como veremos mais adiante, no tocante à questão sobre o arbitrário do signo.

\section{Uma breve contextualização}

Cabe ressaltar que as versões argentina, brasileira e portuguesa foram publicadas em condições de produção distintas daquela em que se deu na França. O percurso histórico que segue às publicações que tocam ao CLG inscreve-se no contexto francês, e muitos estudos organizam a história da linguística em torno do CLG. Desse modo, é preciso considerar que as 
publicações das versões do CLG trabalhadas aqui são muito posteriores à primeira edição francesa, são posteriores também às publicações de edições críticas, às fontes consultadas (a saber, os cadernos dos alunos e as notas de Saussure), bem como às notas saussurianas encontradas depois da publicação do CLG.

De todo modo, reportamo-nos ao estudo de Christian Puech (2016) que aponta diferentes recepções do CLG ao longo desses cem anos na França. O autor considera que o CLG passou por, pelo menos, quatro recepções na França, ou, melhor dizendo, a recepção da referida obra passou por quatro fases principais. A primeira, segundo o autor, foi no momento de publicação do CLG, ainda que não tenha causado nenhum impacto ou reviravolta na comunidade acadêmica. Já a segunda recepção desenvolve-se, especialmente, a partir do I Congresso Internacional dos Linguistas em Haia, realizado em 1928. Apesar de não ter se dado no espaço francês, esse evento, que tomava o CLG como ponto de apoio, contribuiu para a divulgação e a propagação das ideias saussuarianas nos congressos seguintes dos eslavistas. Desse modo, o autor destaca que "os pontos de contato com a França nessa difusão das ideias saussurianas se darão apenas com alguns indivíduos isolados" (PUECH, 2016, p. 17). Além disso, foi a partir dessa segunda recepção que Saussure e o CLG passaram a ser associados aos linguistas estruturalistas, ainda que "o primeiro uso geral (epistemológico e filosófico) do termo 'estruturalismo' se deve a Ernest Cassirer na revista Word em 1945" (PUECH, 2017, p. 17). Já a terceira recepção configura-se pela difusão das ideias saussurianas para fora do estrito círculo de linguistas, especialmente, entre os antropólogos, filósofos e sociólogo. O antropólogo Claude LéviStrauss, por exemplo, foi um dos estudiosos que mais contribuíram para a divulgação do CLG, reivindicando, desse modo, para a Antropologia o caráter de cientificidade a exemplo da Linguística. $O$ antropólogo inspira-se especialmente no princípio do arbitrário do signo linguístico para elaborar um método para a análise dos mitos. E por último, a quarta recepção se dá a partir da publicação dos trabalhos sobre as fontes manuscritas consultadas para elaboração do CLG, como por exemplo, Les sources manuscrites du Cours de Linguistique Générale (1957), de Robert Godel, e a edição crítica do CLG proposta por Rudolf Engler (1968-1974). Segundo Puech (2016, p. 18), a publicação dos manuscritos geraram "uma dinâmica de 'retorno', ao que seria o 'verdadeiro pensamento' de Saussure”. O próprio autor faz uma autocrítica a essa forma bastante esquemática para apresentar as recepções de Saussure na França e salienta que as ideias saussurianas permaneceram, por muito tempo, no anonimato e eram marginalizadas na França e que, só tardiamente, os estudiosos lançaram-se em uma busca do "verdadeiro Saussure" a partir de diferentes manuscritos.

Considerando os diferentes momentos pelos quais passou a obra saussuriana propostos por Puech (2016), no que toca às versões do CLG, tem-se que as primeiras inscrevem-se na segunda recepção, que, como vimos, teve início a partir dos anos 1920. A primeira foi a japonesa, publicada em 1928. A segunda foi a alemã, em 1931, e a terceira foi a russa, em 1933. A versão argentina do CLG, elaborada por Amado Alonso, foi a quarta. Segundo Isaac Salum (2006, p. XIV), "são as edições francesa e espanhola os veículos de maior divulgação do Cours no mundo românico".

O autor da versão argentina do CLG, Amado Alonso, foi um filólogo, crítico literário e linguista. Nascido em Lérin (Navarra), região norte da Espanha, em 1896, mudou-se para a capital Buenos Aires (AR) em 1927 e naturalizou-se argentino, ficando na direção do Instituto de Filologia de Buenos Aires até 1946. A sua versão do CLG foi publicada pela editora argentina Losada ${ }^{1}$, em 1945. De nossa parte, não temos conhecimento de outra versão a não ser a argentina, a elaborada por Amado Alonso.

$1<\mathrm{http} / / /$ www.editoriallosada.com/>. 
Já a versão publicada no Brasil, em 1970, realizada por Antônio Chelini, José Paulo Paes e Izidoro Blikstein, com prefácio à edição brasileira de Isaac Nicolau Salum, foi publicada pela editora Cultrix, de São Paulo, e co-editada pela editora da Universidade de São Paulo.

A versão do CLG em Portugal ocorreu em 1971, um ano após a versão brasileira; foi realizada por José Victor Adragão e publicada pela editora Edições Dom Quixote, de Lisboa. O prefácio à edição portuguesa é elaborado pelo próprio Adragão.

Conhecemos ainda duas versões: a versão de Wade Baskin, publicada em 1959, nos Estados Unidos, e a de Roy Harris, publicada em 1983, na Inglaterra. Há vários estudos publicados sobre a diferença entre essas duas versões, especialmente no que toca à versão (francês-inglês) dos conceitos langue, langage et parole. A versão britânica parece ter sido motivada a partir de um descontentamento em relação à versão americana. Em cada uma das versões, esses conceitos, especificamente, são postos de forma bem diferente, o que despertou muitas discussões, uma vez que a versão escolhida aponta para um gesto interpretativo do autor da versão em relação à obra saussuriana.

\section{A versão do CLG na Argentina}

Quando o CLG é publicado por Amado Alonso, em 1945, na Argentina, tem-se, na Europa, uma fase de efervescência do movimento estruturalista, o qual começa a ganhar força. No prólogo à edição argentina, Amado Alonso ressalta o caráter científico e positivista do CLG e também a importância do movimento estruturalista. 0 autor de tal versão não esconde o seu entusiasmo com a obra saussuriana e afirma que "sí, éste será siempre un libro clásico en la ciencia del lengage" (ALONSO, 2015, p. 10). Já no início do prólogo, Amado Alonso destaca o caráter científico da obra, o qual é reiterado frequentemente: "El Cours de linguística Geral de Ferdinand de
Saussure es el mejor cuerpo organizado de doctrinas lingüísticas que ha producido el positivismo; el más profundo y a la vez el más clarificador. Es la suya uma posición científica positivista"2 (ALONSO, 2015, p. 7 [grifo nosso]).

Entretanto, esse mesmo caráter positivista ressaltado no início é alvo de críticas na sequência. O filólogo considera que o CLG não tem uma base filosófica, uma vez que a obra pretende-se mais científica que filosófica. Partindo desse pressuposto, ele faz várias críticas em relação às renúncias feitas pelo mestre genebrino, decorrentes de tal escolha. Por exemplo, sobre a separação entre langue e parole e o privilégio da primeira sobre a segunda, Alonso (2015, p.11) considera o aspecto positivo e o negativo dessa delimitação: "la lingüística de Saussure llega a una sorprendente claridad y simplicidad, pero a fuerza de eliminaciones, más aún, a costa de descartar lo esencial en el lenguaje (el espíritu) como fenómeno específicamente humano"3.

O filólogo lamenta a exclusão ("descartar lo esencial [...]") da fala, a qual é pressuposta a partir da separação entre langue e parole. Além disso, questiona se tais dicotomias, assim como diacronia e sincronia, poderiam mesmo ser separadas e consideradas sem nenhum contato. Essas separações parecem surpreender o filólogo, o qual aponta que "esta sorprendente concepción de lãs relaciones - de la falta de relación directa entre la diacronia y la sincronia deslumbro a algunos, desconcertó a otros y por fin desató la oposición más viva y general”4 (ALONSO, 2015, p. 13).

Considerando a data de publicação da primeira edição da obra, a referida versão é anterior à publicação dos textos exegéticos e das fontes

2 Tradução nossa: “O Curso de Linguística Geral de Ferdinand de Saussure é o melhor corpo organizado de doutrinas linguísticas que produziu o positivismo; o mais profundo e, ao mesmo tempo, o mais esclarecedor. É uma posição científica positivista".

3 Tradução nossa: "a lingüística de Saussure chega a uma clareza e simplicidade surpreendentes, mas a força das eliminações, ainda mais, à custa de descartar o essencial na linguagem (o espírito) como um fenômeno especificamente humano".

Tradução nossa: "essa surpreendente concepção das relações - da falta de relação direta - entre a diacronia e a sincronia deslumbrou alguns, desconcertou outros e, finalmente, desencadeou a oposição mais viva e geral". 
manuscritas do CLG. Uma crítica apontada pelo filólogo ao CLG é atribuída não ao processo de edição, mas à morte prematura do autor (leia-se Ferdinand de Saussure). Segundo Alonso (2015, p. 9),

bien es verdad que, fuera del capítulo donde se expone, no interviene ya esta concepción en la marche del libro, sino más bien el asociacionismo herbartiano de los Neogramáticos; pero es evidente que esta incongruencia del Curso es achacable a la prematura muerte del autor. ${ }^{5}$

Em nota de rodapé, o filólogo destaca que esse aspecto é ainda mais visível na exposição sobre o circuito da fala. Os editores do CLG, Charles Bally e Albert Sechehaye, são citados por ele não como editores e organizadores da obra, mas como "ortodoxos saussureanos" (saussurianos ortodoxos), ao lado de outros autores, franceses e suíços principalmente, como Antoine Meillet e Joseph Vendryes, os quais, segundo Alonso (2015, p. 10), "lo han acatado como el código supremo del saber teórico y de la orientación en los métodos"6. O filólogo deixa para mencionar, já ao final do prólogo, que não foi Saussure quem, de fato, escreveu e publicou a obra. Ao fazer conjecturas sobre o destino das ideias do mestre genebrino, ele questiona-se:

Quién sabe hasta dónde las habría prolongado o hacia dónde rectificado el mismo Saussure si la muerte le hubiera dado el tiempo que su conciencia tan escrupulosa requería, si él mismo hubiera por lo menos escrito su libro! Y sobre todo, si, escrito por él y publicado, hubiera tenido ocasión de participar en las pruebas y contrastaciones a que la crítica ha ido sometiendo sus doctrinas (ALONSO, 2015, p. 23). ${ }^{7}$

\footnotetext{
5 Tradução nossa: "É verdade que, fora do capítulo onde está exposto, essa concepção não intervém na linearidade do livro, mas sim a associação herbartiana dos Neogramáticos; mas é evidente que essa incongruência do Curso é atribuível à morte prematura do autor".

6 Tradução nossa: "aceitaram-no como o código supremo de saber teórico e da orientação em métodos". Tradução nossa: "Quem sabe quanto tempo Saussure os teria prolongado ou onde teria retificado, se a morte lhe tivesse dado o tempo que sua consciência tão escrupulosamente exigia, se ele tivesse ese a pelo mes seu livro! E acima de tudo, se escrito por to e publicado tivesse tido ocasião de participar das provas e dos debates aos quais a crítica tem submetido suas doutrinas".
}

Além disso, o referido filólogo detém-se sobre a concepção de língua enquanto sistema, a qual é retomada sob um viés estruturalista, como é ressaltado no seguinte fragmento: "Pienso en su rigurosa concepción estructuralista de las lenguas como sistemas [...]” (ALONSO, 2015, p. 8 [itálico do filólogo]). Mais adiante, Alonso, ao mencionar o I Congresso Internacional de Linguistas de Haya, realizado em 1928, afirma que os fonólogos do Círculo Linguístico de Praga têm "la misma concepción estructuralista que Saussure para el sistema de la lengua"8 (ALONSO, 2015, p. 13). Em ambas passagens, o autor faz menção à "concepção estruturalista" de Saussure sobre língua enquanto sistema. Segundo ele, a concepção estruturalista já estava presente na obra saussuriana antes mesmo do movimento estruturalista. 0 termo "estruturalismo" é demasiadamente problemático, e muito já se discutiu sobre isso. Patrick Sériot (2016) é um dos autores que questiona a série de mal-entendidos em torno desse termo, especialmente aquela história do estruturalismo linguístico contada a partir dos intelectuais parisiense dos anos 1960. Segundo o autor,

é, com efeito, uma espécie de lugar-comum no mundo ocidental considerar a história do estruturalismo como uma evolução linear, a partir de Saussure e indo em direção a C. Lévi-Strauss e R. Barthes, passando por espécies de elos intermediários entre Praga e Copenhage, nos anos 1920 e 1930 (SERIÓT, 2016, p. 26).

Além disso, o autor ressalta o desconcerto de Roman Jakobson e de Trubetzkoy ao serem apontados como continuadores da "escola" de Saussure e, em tom de ironia, questiona: "o Círculo de Praga seria 'saussuriano sem o saber?" (SÉRIOT, 2016, p. 42), em alusão à - sempre atual e problemática pergunta se Saussure seria estruturalista sem o saber. 0 que questionamos aqui é como a interpretação de um Saussure estruturalista (sem sê-lo)

8 Tradução nossa: "a mesma concepção estruturalista que Saussure para o sistema da língua”. 
perpetua-se na história da Linguística, direcionando assim a leitura da obra; além disso, como essa interpretação constitui-se como um já-dito, uma voz sem nome, que não se ousa questionar. No contexto brasileiro, temos um trabalho realizado por Scherer (2016) que também vai mostrar os ecos de um possível Saussure estruturalista.

Portanto, a partir de Amado Alonso, podemos considerar que o Curso, dirigido ao público hispanófono, é e será sempre uma obra estruturalista e positivista.

\section{A versão do CLG no Brasil}

O CLG possui uma grande importância histórica para a consolidação daquilo que hoje chamamos de Linguística Moderna e sua disciplinarização no Brasil. Como sabemos, a Linguística passa a ser disciplina a partir de 1962, por meio de um decreto/portaria que a torna disciplina obrigatória nos currículos nos cursos de Letras. Entretanto, a versão da obra que dá visibilidade às pesquisas linguísticas e coloca a própria Linguística entre as ciências humanas, o CLG, faz-se presente bem tardiamente no Brasil: será em 1970, época em que o estruturalismo linguístico europeu tinha ainda grande destaque, embora já estivesse submetido a vários questionamentos. Lembramos que, em relação ao CLG e seu complexo processo de edição, havia então muitas publicações e algumas edições críticas que apontavam as divergências entre o CLG, as fontes consultadas e alguns manuscritos saussurianos. No contexto brasileiro, as discussões em relação aos manuscritos e às fontes do CLG são mantidas limitadas a um pequeno círculo de linguistas. Mesmo as críticas em relação às contradições da própria obra são veladas.

A versão do CLG, em 1970, no Brasil, representa um grande impacto sobre os programas da disciplina de linguística, como bem referem Scherer, Schneiders, Martins (2015). As autoras, ao analisarem os programas de linguística em universidades do sul do Brasil, realizam um estudo comparativo entre o antes e o depois da versão brasileira do CLG, apontando algumas mudanças significativas nos respectivos programas. De fato, o processo de disciplinarização de um dado saber depende de vários fatores e pode se estender em um longo horizonte até sua implementação como disciplina. Poderíamos afirmar que as ideias saussurianas são introduzidas no Brasil na década de 1930, e uma parte delas assim o fora por aqueles que estavam muito ligados aos intelectuais franceses e portugueses, como indicam as autoras anteriormente citadas.

No prefácio à edição brasileira, Isaac Salum trata sobre algumas versões do CLG para outras línguas e ressalta a importância desse gesto para a divulgação da obra. Segundo Salum:

A primeira foi a versão japonesa de H. Kobayashi, de 1928, reeditada em 1940, 1941 e 1950. Vem depois a alemã de H. Lommel, em 1931, depois a russa, de H. M. Suhotin, em 1933. Uma divulgou-o no Oriente, e a outra no mundo germânico (e nórdico) e a terceira no mundo eslavo. A versão espanhola, de Amado Alonso, enriquecida com um excelente prefácio de 23 páginas, saiu em 1945, sucedendo-se as edições de 1955, 1959, 1961, 1965 e 1967, numa cerrada competição com as edições francesas. São as edições francesa e espanhola os veículos de maior divulgação do Cours no mundo românico (SALUM, 2006, p. XIII-XIV).

A versão e a respectiva publicação do CLG no Brasil coincidem, como já assinalamos, com o momento em que, na Europa, o movimento estruturalista é duramente criticado; há inúmeras publicações sobre o CLG, referindo-se, mais especificamente, às fontes consultadas e aos manuscritos encontrados posteriormente. De todo modo, a versão brasileira é considerada, por Isaac Salum, como atrasada. De fato, são 54 anos de atraso, como salienta o autor, em relação à época de publicação do CLG, em 1916. Entretanto, se considerarmos a conjuntura histórica dos estudos linguísticos no Brasil, talvez essa margem de atraso possa ser vista a partir de um outro horizonte de retrospecção. 
Salum, no prefácio à edição brasileira, ressalta o processo de edição da obra sobre o qual fora concebida. Isto, à primeira vista, que poderia pesar contra a obra, é usado como uma propriedade a favor: é quando Salum compara Saussure a outras personalidades históricas, também eminentes, como Sócrates e Jesus.

Saussure - como Sócrates e Jesus - é recebido de "segunda mão". Conhecemos Sócrates pelo que Xenofonte e Platão escreveram como sendo dele. 0 primeiro era muito pouco filósofo para entendê-lo, o segundo filósofo demais para não ir além dele, ambos distorcendo-o. Jesus nada escreveu senão na areia: seus ensinos são o que nos transmitiram seus discípulos, alguns dos quais não foram testemunhas oculares (SALUM, p. XVI).

A comparação de Saussure com Jesus parece ser recorrente entre os linguistas saussurianos. Trabant (2005) leva ainda mais longe a comparação entre o livro que contém palavra de Jesus e aquele que contém a palavra de Saussure, ponderando que "de toute façon, ce qui est vrai pour les Évangelis l'est aussi pour le Cours de linguistique générale: ce texte peu 'authentique' fait foi"9 (TRABANT, 2005, p. 116). Entretanto, o autor considera ainda que os linguistas saussurianos estão em vantagem em relação aos evangelistas, já que foram encontrados os manuscritos de Saussure, ao passo que jamais se poderia encontrar manuscritos de Jesus, pois este não escreveu senão na areia. Em tom de gracejo, o autor insiste na comparação e aponta que:

Mais pour les Évangelis nous sommes dans l'heureuse situation de ne pas avoir trouvé, post festum, des notes manuscrites de la main de Jesus. Le texte des Évangelis prête déjà assez à des interprétations différentes et à des malentendus terribles. On n'ose pas penser aux guerres de la religion

\footnotetext{
9 Tradução nossa: "De qualquer modo, o que é verdade para os evangelistas o é também para o Curso de Linguística Geral: este texto pouco 'autêntico' faz fé".
}

qu'aurait générées la découverte des manuscrits de Jésus. Serait-ce qui risque d'arriver autour du Cours de linguistique générale? ${ }^{10}$ (TRABANT, 2005, p. 116).

Felizmente, não é da natureza dos linguistas promover uma violência, os quais não têm em seu histórico nenhum registro de guerras ou de que, em algum momento, pegou-se em armas para defender uma ou outra causa. Por outro lado, guerras de palavras sempre há, pois é no mundo das palavras que se inscreve o trabalho nosso como linguista e analistas de discurso.

Brincadeiras à parte, Salum salienta o processo de edição da obra, começando pelo início, a saber, as aulas ministradas por Saussure, entre 1907 e 1911, na Universidade de Genebra. Além disso, Salum destaca que, segundo as fontes e outros manuscritos saussurianos publicados, Saussure não estava satisfeito com o desenvolvimento da matéria por diversas razões. E, em relação ao resultado do processo de edição, Salum não modaliza positivamente suas palavras e afirma que:

sobre essas duas deformações do pensamento de Saussure - a que ele fazia para os estudantes e a que eles faziam no anotar aproximadamente - soma-se a organização da matéria por dois discípulos, ilustres, mas que declaram não terem estado presentes aos cursos [...]. Aí está um problema crítico com tríplice complicação. Problema crítico grave como o da exegese platônica ou o problema sinótico dos Evangelhos (SALUM, 2006, p. XVIII).

Salum comenta ainda sobre as inúmeras publicações exegéticas dos manuscritos saussurianos que serviram de fonte para a elaboração do CLG, além de outros manuscritos que só foram encontrados posteriormente. De

${ }^{10}$ Tradução nossa: “Mas para os evangelistas nós estamos na feliz situação de não ter encontrado, post festum, notas manuscritas da mão de Jesus. 0 texto dos evangelistas presta-se a muitas interpretaç̃ diferentes e a mal-entendidos terríveis. Não ousamos pensar em guerras da religião que teriam gerado

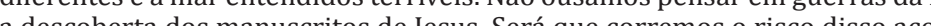
de Linguística Geral?" 
todo modo, Salum (2006, p. XXII) reconhece que "ainda que novas soluções se ofereçam para as oposições saussurianas, Saussure está longe de vir a ser superado". Além disso, ao final, Salum sugere algumas obras ao (potencial) leitor que poderão auxiliá-lo na compreensão do CLG e também oferece uma análise crítica. Entre as obras recomendadas, cuja maioria está publicada na França, Salum destaca: Saussure ou le structuraliste sans le savoir présentation, choix textes, bibliographic (1968), de Georges Mounin. Em relação a essa obra, Salum (2006, p. XXIII) considera que "a nosso ver, tem de defeituoso apenas o título, pois Saussure foi antes 'estruturalista antes do termo', que Mounin poderia dizer à francesa le structuraliste avant la lettre". Salum, assim como Mounin e tantos outros, avalia que Saussure era um estruturalista antes mesmo que esse pudesse a vir a existir. Nessa leitura, não se nega que o movimento estruturalista seja posterior à publicação do CLG e que o mesmo contribuiu para pensá-lo, o que se afirma é que Saussure já era um estruturalista ainda que seja anterior e não tenha usado a nomeação.

\section{A versão do CLG em Portugal}

Na versão portuguesa do CLG, José Victor Adragão, na "nota introdutória à tradução portuguesa", comenta, inicialmente, o quão controverso pode ser versar uma obra do início do século XX para um público específico. $\mathrm{O}$ responsável pela versão portuguesa destaca os questionamentos que se impuseram durante tal processo:

como traduzir o Cours? Duas hipóteses pareciam ideais: seguir literalmente o original ou adaptá-lo a uma linguística dos nossos dias, mantendo o que nele é válido e suprimindo ou corrigindo as poucas páginas que a experiência de cinquenta anos considera desatualizadas ou caduca (ADRAGÃO, 1971, p. 19)
Em um primeiro momento, tivemos receio de que a segunda opção tivesse sido escolhida e pareceu-nos que, mais uma vez, as ideias de Saussure estivessem fadadas à interpretação, não só dos editores, mas também daqueles que fizeram sua versão. Assim, ocorreu-nos o seguinte questionamento, parafraseando Trabant (2005), e recordando o risco de que já nos alertava o autor (ainda que o próprio autor não ousasse pensar nessa possibilidade): seria necessário defender Saussure de seus autores das mais distintas versões?

Felizmente, o próprio autor da versão em Portugal tranquiliza-nos e afirma que "a presente edição não corresponde a uma nem a outra das hipóteses apontadas" (ADRAGÃO, 1971, p. 20). Tranquilidade que não dura muito, porque logo se impõe uma dúvida, sobre qual procedimento ele tomou como parâmetro. Segundo ele, "procurou-se uma adaptação em alguns pontos, mormente nos exemplos ilustrativos" (p. 20).

Entretanto, "as adaptações" (nomeação usada por ele e que nos inquieta) que não se limitam apenas aos exemplos, estendem-se às transcrições fonéticas, as quais "foram objecto de especial atenção [...] e, por isso, surge, a pp. 117 um 2o apêndice aos Princípios de Fonologia" (ADRAGÃO, 1971, p. 20). Esse apêndice é um acréscimo presente apenas na edição portuguesa, resultante da intervenção do referido autor da versão publicada. Esse acréscimo justifica-se principalmente porque, nos exemplos referentes ao significante, ele, diferentemente da edição francesa, tomou por meta utilizar a transcrição fonética. Aliás, os exemplos e as transcrições fonéticas estão em uma estreita relação, uma vez que tal meta é constantemente retomada para ilustrar exemplos que são citados na obra, aspecto esse que observaremos mais adiante, na sequência do presente artigo.

Entre os acréscimos da edição portuguesa, tem-se também, ao final do livro, uma bibliografia utilizada para a sua dita adaptação. São referenciadas obras publicadas em Portugal, na Espanha e na Inglaterra. Essas obras são, 
em sua maioria, gramáticas (históricas, principalmente), dicionários, obras sobre diversos temas, todas datadas entre os anos 1930 e 1970, com exceção da obra Exposição da Pronúncia Normal Portuguesa, de Gonçalves Viana, datada de 1892. Aliás, essa última obra despertou-nos mais uma curiosidade, aquela no tocante ao seu argumento, o que veremos a seguir. No início da nota introdutória, Adragão (1971, p. 19) faz referência à antiguidade do CLG e o quanto é desafiador produzir a versão de uma obra com uma defasagem de mais de meio século. Entretanto, ele próprio toma como referência uma obra, datada do século XIX, muito anterior à publicação do CLG. Não entraremos aqui na discussão sobre a pertinência ou não da obra, apenas nos limitaremos a indicar o efeito contraditório do sujeito responsável pela versão em Portugal ao retomar uma obra portuguesa ainda mais antiga para "adaptar" a versão francesa para o contexto português e a sua atualidade.

Já quanto às condições históricas (conjuntura política ideológica e institucional), poucos sabemos do trabalho de tal versão. Parece que o maior problema para Adragão será mesmo a compreensão das ideias do mestre genebrino quando desse processo, ou seja, a "adaptação" de uma obra "antiga" ao contexto contemporâneo português.

\section{A versão do arbitrário do signo}

Uma das passagens do CLG que rendeu muitas discussões foi o exemplo usado para ilustrar o princípio do arbitrário do signo. Curiosamente, no CLG, é referido que o princípio do arbitrário do signo não é contestado por ninguém. Na obra em questão, o princípio do arbitrário do signo é sustentado pela ausência de um vínculo necessário/natural entre as duas unidades que constituem o signo, a saber, o significado e o significante. Para ilustrar esse princípio, na versão publicada na França e que estamos estudando, é dado o seguinte exemplo:
Ainsi l'idée de "soeur" n'est liée par auncun rapport intérieur avec la suite de sons s-ö-r que lui sert de signifiant; il pourrait être aussi bien représenté par n'importe quelle autre: à preuve les différences entre les langues et l'existence même de langues différentes: le signifié «boeuf» a pour signifiant b-ö-f d'un côté de la frontière, et o-k-s (Ochs) de l'autre (SAUSSURE, 1995, p. 100).

Esse exemplo, no entanto, parece reintroduzir o referente, elemento que não faz parte da constituição do signo linguístico e que não é contemplado na definição imanente de língua enquanto sistema de signos. Benveniste (1976), no seu artigo $A$ natureza do signo linguístico, cuja primeira publicação data de 1936, é um dos primeiros linguistas a contestar esse exemplo. O linguista sustenta que o exemplo usado estaria em flagrante contradição com a definição de signo linguístico, a qual recusa o referente. Para Benveniste (1976), o exemplo usado coloca novamente em cena o referente na sua relação com a língua. Em um estudo mais recente (COSTA, 2013), detemo-nos mais demoradamente sobre as longas discussões entre os linguistas acerca dessa controversa passagem do CLG. Neste trabalho, não nos alongaremos sobre ela.

Para nós, o próprio exemplo implica a problemática de um gesto de leitura, de uma possível versão, uma vez que se coloca em relação designações em línguas outras para apontar um mesmo referente. Para situar nosso leitor, antes de prosseguirmos em nosso estudo, retomaremos a passagem acima referida na edição francesa do CLG e as versões argentina, portuguesa e brasileira, conforme o Quadro 1 adiante.

O princípio do arbitrário sustenta que não há nenhuma relação necessária entre significado e significante, de modo que a ideia de "soeur" poderia estar perfeitamente associada a outro significante. Entretanto, para ilustrá-lo, não é tão simples quanto possa parecer e, para aquele que está imbuído de se fazer entender na versão possível para os leitores 
Quadro 1 - Proposição nossa

\begin{tabular}{|c|c|c|c|}
\hline $\begin{array}{l}\text { Cours de Linguistique Générale } \\
\text { Editado por Charles Bally e Albert Sechehaye }\end{array}$ & $\begin{array}{l}\text { Curso de Linguística General } \\
\text { Versão de Amado Alonso }\end{array}$ & $\begin{array}{l}\text { Curso de Linguística Geral } \\
\text { Versão de Antônio Chelini, José Paulo Paes e } \\
\text { Izidoro Blikstein }\end{array}$ & $\begin{array}{l}\text { Curso de Linguística Geral } \\
\text { Versão de José Victor Adragão }\end{array}$ \\
\hline $\begin{array}{l}\text { Ainsi l'idée de "soeur" n'est liée par auncun } \\
\text { rapport intérieur avec la suite de sons s-ö-r que } \\
\text { lui sert de signifiant; il pourrait être aussi bien } \\
\text { représenté par n'importe quelle autre: à preuve } \\
\text { les différences entre les langues et l'existence } \\
\text { même de langues différentes: le signifié "boeuf" } \\
\text { a pour signifiant b-ö-f d'un côté de la frontière, et } \\
\text { o-k-s (Ochs) de l'autre. } \\
\text { (p. 100) }\end{array}$ & $\begin{array}{l}\text { Así, la idea de sur no está ligada por relación } \\
\text { alguna interior con la secuencia de sonidos } \\
s-u-r \text { que le sirve de significante; podría estar } \\
\text { representada tan perfectamente por cualquier } \\
\text { otra secuencia de sonidos. Sirvan de prueba } \\
\text { las diferencias entre las lenguas y la existencia } \\
\text { misma de lenguas diferentes: el significado 'buey' } \\
\text { tiene por significante bwéi a un lado de la frontera } \\
\text { franco-española y böf (boeuf) al otro, y al otro } \\
\text { lado dela frontera francogermana es oks (Ochs). } \\
\text { (p. 144) }\end{array}$ & $\begin{array}{l}\text { Assim, a idéia de "mar" não está ligada por } \\
\text { relação alguma interior à seqüência de sons } \\
\text { m-a-r que lhe serve de significante; poderia } \\
\text { ser representada igualmente bem por outra } \\
\text { seqüência, não importa qual; como prova, } \\
\text { temos as diferenças entre as línguas e a própria } \\
\text { existência de línguas diferentes: o significado } \\
\text { da palavra francesa boeuf ("boi") tem por } \\
\text { significante b-ö-f de um lado da fronteira franco- } \\
\text { germânica, e o-k-s (Ochs) do outro. } \\
\text { (p. 82) }\end{array}$ & $\begin{array}{l}\text { Assim, a idéia de "pé" não está ligada por } \\
\text { nenhuma relação à cadeia de sons [p] + [ع] que } \\
\text { lhe serve de significante; podia ser tão bem } \\
\text { representada por qualquer outra: provam-no as } \\
\text { diferenças entre as línguas e a própria existência } \\
\text { de línguas diferentes: o significado "rua" tem } \\
\text { como significante [rue] dum lado da fronteira e } \\
\text { [kaKe] do outro. } \\
\text { (p.124) }\end{array}$ \\
\hline
\end{tabular}

em sua língua, torna-se mais difícil ainda. Para ilustrar tal problema de compreensão e explicação, trazemos o apoio de Michel Arrivé (2010, p. 61), que se pergunta sobre o mesmo ponto:

Mas como provar essa ausência de "acordo interior", visto que justamente o significado "irmã" não tem em português outro significante além de $i$ - $r$ $m$-ã? Mencionar um sinônimo? Mas justamente, ele não tem sinônimo, dado que os pretensos sinônimos só têm valor próprio por sua oposição (CLG, 160). 0 único meio que parece se impor é o de apelar a outra língua.

Do mesmo modo que o exemplo expõe a relação entre outras línguas e a responsabilidade daquele que está vivenciando o processo de descrever, compreender e interpretar (nas categorias pêcheutianas) (PÊCHEUX, 1990), despertou-nos a curiosidade de como, a partir de línguas outras, se poderia refletir sobre ele. A nosso ver, esse exemplo sobre a arbitrariedade traz em seu bojo a problemática da alteridade, do colocar-se no lugar do outro e desnaturalizar tais relações com e sobre a língua, língua nossa que (quase) nunca ousamos questionar.
Na edição francesa, considera-se o exemplo "soeur" (irmã) e "boeuf" (boi), sendo que é o segundo o maior causador de desentendimento, quando colocado, enquanto significado, em relação aos significantes "b-ö-f" e "o-k-s". Faz-se alusão à fronteira entre países de línguas diferentes, mas não se designa tal fronteira, ela é apenas uma direção de sentidos a partir dos exemplos apontados, do francês e do alemão.

Já na versão argentina, o exemplo "soeur" é substituído pelo exemplo espanhol "sur" (sul), enquanto o segundo exemplo, "boeuf", é substituído por "buey" (do espanhol "boi"), que tem como significantes "bwéi", de um lado da fronteira franco-espanhola, e "boeuf", de outro. No caso da versão argentina, cabe ressaltar, a fronteira referida na edição francesa é acrescida de uma designação que a especifica. Na verdade, são referidas duas fronteiras, a fronteira franco-espanhola e a fronteira franco-germânica. O exemplo proposto na versão argentina não aponta apenas para um gesto de interpretação, mas também para uma forma de se colocar no mundo em relação ao outro. Alonso toma como exemplo um signo (buey) da língua falada na Espanha, uma vez que a fronteira é acrescida de uma designação, 
"frontera franco-española", para sinalizar a fronteira entre França e Espanha, e "frontera francogermana", em alusão à fronteira entre França e Alemanha. Os exemplos considerados são buey (espanhol), boeuf (francês) e ochs (alemão) para apontar como o sujeito designa o referente a partir de uma dada língua. 0 que vemos é um Alonso mais de terras e língua espanhola do que um Alonso argentino no Novo Mundo. É o Velho Mundo procurando as fissuras do inconsciente nas margens da língua e de uma nação, mas não aquelas em que ele se naturalizou. Na língua, nada é da ordem do natural, pois ela é sempre da ordem da memória e das relações do sujeito com ela mesma. Naquilo que repetimos desde o início, a alteridade sem limites e sem fronteiras.

Por outro lado, as críticas voltadas a esse exemplo na edição francesa recaem na questão de que Saussure não ilustra a arbitrariedade entre significado e significante, mas entre o signo e o referente. E o referente, como sabemos, não faz parte da constituição do signo linguístico saussuriano.

Na versão brasileira, o exemplo "soeur" é substituído por "mar", ao passo que os exemplos seguintes apontados na edição francesa são mantidos (parcialmente). Cabe ressaltar que, assim como na versão argentina, há um acréscimo acerca da designação da fronteira. Mantém-se o exemplo em francês "boeuf" e faz-se referência à fronteira franco-germânica, onde se tem como significante "b-ö-f" (francês), de um lado, e "o-k-s" (alemão) de outro.

Na versão portuguesa, o exemplo "soeur" é substituído por "pé", e "boeuf" é substituído por "rua", mas o que diferencia essa tradução das demais, especialmente em relação à edição francesa, é a adoção da transcrição fonética. A forma de descrever a sequência de sons "p-é", que remete ao significante, parece estar diretamente relacionada à pronúncia. Em relação ao segundo exemplo, toma-se um signo do português, "rua", e compara-se com o do espanhol "calle", uma vez que Portugal só faz fronteira com a Espanha. Esse exemplo, quando inscrito na versão portuguesa, traz mais do que uma relação de alteridade entre línguas. Ele coloca também uma questão conceitual e retoma, de um certo modo, a problemática acerca da terminologia do signo linguístico, não desenvolvida no CLG (apenas sinalizada), mas bastante frequente nos Escritos de Linguística Geral (2012): o signo considerado como um todo (significado e significante) ou apenas o significante?

\section{Para concluir}

O que essa escolha sobre como descrever o significante pode nos dizer acerca do gesto interpretativo do sujeito? O significante poderia ser um ponto possível para se retomar a relação entre língua e fala? Como vimos, trata-se de uma questão problemática no CLG, uma vez que o princípio do arbitrário do signo nunca pode ser demonstrado, dada a natureza fugidia do significado, principalmente, que parece ser ainda mais irrepresentável que o significante, como apontam os intensos debates acerca dos esquemas propostos no CLG para ilustrar o signo linguístico. Questão problemática também porque a fronteira da e sobre a língua não é apenas uma fronteira física e geográfica, como parecem sugerir as diferentes versões. O que temos é uma fronteira política de/para lidarmos com a língua, uma compreensão do que somos enquanto língua e sujeito na história do conhecimento sobre a língua e sobre teorias linguísticas.

Cabe considerarmos ainda que o horizonte de projeção que nos propõe Auroux (2006) ajuda-nos a entender melhor como a circulação de um Saussure estruturalista, e algumas vezes positivista, tem a ver - e muito com o como se dá a divulgação do conhecimento sobre um autor em um movimento que não é linear tampouco objetivo, mas que é constitutivo 
do como se produz a interpretação de determinados fatos históricos e institucionais, pois como assegura Sériot (2016):

Em ciências humanas, os movimentos de ideias entre os países não se fazem em perfeita sincronia. Há defasagens na recepção das obras, frequentemente defasagens ideológicas e não técnicas (os livros circulam, são traduzidos). É por isso que é preciso reconstituir todo um fundo de polêmicas vivas, do qual nos chegam atualmente apenas ecos abafados, mas que constituem contudo o barulho de fundo distorcido de nossas próprias discussões, como o 'barulho das estrelas' que os radiotelescópios captam do espaço, sobre os quais nascem os nossos próprios conceitos (SÉRIOT, 2016, p. 47)

\section{Referências}

ADRAGÃO, J. V. Nota introdutória à tradução portuguesa. In: SAUSSURE, F. Curso de Linguística Geral. Organizado e editado por Charles Bally e Albert Sechehaye. Tradução de Victor Adragão. Porto: Dom Quixote, 1971. p. 19-20.

ALONSO, A. Prólogo a la edición española. In: SAUSSURE, F. Curso de Linguística General. Organizado e editado por Charles Bally e Albert Sechehaye. Tradução de Amado Alonso. Buenos Aires: Losada, 2015. p. 07-31.

ARRIVÉ, M. À procura de Ferdinand de Saussure. São Paulo: Parábola Editorial, 2010.

AUROUX, S. Les méthodes d'historicisation in Histoire Epistémologie Langage, tome XXVIII, Fascicule 1, (2006) SHESL Paris. p. 104-116.

BENVENISTE, É. Problemas de lingüística geral. Tradução de Maria da Glória Novak e Luiza Néri. São Paulo: Companhia Editora Nacional, Editora da Universidade de São Paulo, 1976.

COSTA, M. I. S. Saussure e o Curso de Linguística Geral: uma relação de nunca acabar. Línguas e instrumentos lingüísticos, n. 31, p. 107-116, jan.-jul. 2013.

GODEL, R. Les sources manuscrites du Cours de Linguistique Générale. Front Cover: Librairie Droz, 1957.

PÊCHEUX, M. O discurso estrutura ou acontecimento. (original Discourse: structure or Event? 1988). Tradução de Eni P. Orlandi. Pontes: São Paulo, 1990.
PUECH, C. O discurso, as heranças e os destinos de Saussure na França. In: CRUZ, A.; PIOVAZANI, C.; TESTENOIRE, P-Y. Saussure, o texto e o discurso: cem anos de heranças e recepções. São Paulo: Parábola, 2016. p. 13-37.

SALUM, I. Prefácio à edição brasileira. In: SAUSSURE, F. Curso de linguística Geral. 27. ed. Organizado e editado por Charles Bally e Albert Sechehaye. Tradução de Antônio Chelini, José Paulo Paes e Izidoro Blikstein. São Paulo: Cultrix, 2006. p. XIII-XXIII.

SAUSSURE, F. Curso de Linguística General. Organizado e editado por Charles Bally e Albert Sechehaye. Tradução de Amado Alonso. Buenos Aires: Losada, 2015

SAUSSURE, F. Escritos de linguística Geral. Organizado e editado por Simon Bouquet e Rudolf Engler. São Paulo: Cultrix, 2012.

SAUSSURE, F. Curso de linguística Geral. 27. ed. Organizado e editado por Charles Bally e Albert Sechehaye. Tradução de Antônio Chelini, José Paulo Paes e Izidoro Blikstein. São Paulo: Cultrix, 2006.

SAUSSURE, F. Cours de Linguistique Générale. Organizado e editado por Charles Bally e Albert Sechehaye. Paris: Payot \& Rivages, 1974.

SAUSSURE, F. Curso de Linguística Geral. Organizado e editado por Charles Bally e Albert Sechehaye. Tradução de Victor Adragão. Porto: Dom Quixote, 1971.

SCHERER, A. Estrutura/sistema: eis uma questão para os estudos linguísticos do ponto de vista da história da Linguística. In: SOUZA, Lucília Maria Abrahão e; NAGEM, Glaucia; BALDINI, Lauro. A palavra de Saussure. São Carlos: Pedro \& João Editores, 2016. p. 77-92. SCHERER, A; SCHNEIDERS, C.; MARTINS, T. Saussure e os estudos saussurianos no sul: algumas reflexões. Línguas e Instrumentos Linguísticos, n. 35, p. 73-94, jan.-jun. 2015.

SÉRIOT, P. Estrutura e totalidade. Tradução de Maristela Cury Sarian e Mariângela P. C. G. Joanilho. Campinas; Cáceres: Editora da Unicamp; UNEMAT, 2016.

TRABANT, J. Faut-il défendre Saussure contre ses amateurs? Notes item sur l'étymologie saussurienne. In: Langages, 39e année, n. 159. 2005. Linguistique et poétique du discours. À partir de Saussure, sous la direction de Jean-Louis Chiss et Gérard Dessons. p. 111124. Disponível em: <www.persee.fr/doc/lgge_0458-726x_2005_num_39_159_2655>.

Recebido em 12/01/2018

Aceito em 25/03/2018. 